\title{
Two-hybrid assay: construction of an Escherichia coli system to quantify homodimerization ability in vivo
}

\author{
G. Di Lallo, ${ }^{1}$ P. Ghelardini² and L. Paolozzi ${ }^{1}$ \\ Author for correspondence: L. Paolozzi. Tel: +39 06 72594325. Fax: +39062023500. \\ e-mail:paolozzi@bio.uniroma2.it
}

\begin{abstract}
1 Dipartimento di Biologia, Università 'Tor Vergata' Roma, Via della Ricerca Scientifica, 00133 La Romanina (Roma), Italy

2 Centro Acidi Nucleici del CNR, Roma, Italy
\end{abstract}

\begin{abstract}
A hybrid system which takes advantage of the properties of the $\lambda$ repressor allows detection of protein-protein interactions. Fusion of the $\mathrm{cl} \mathrm{N}$-terminal domain to a heterologous protein will result in a functional $\lambda$ repressor, able to strongly bind to its operator and conferring immunity to $\lambda$ infection only when the heterologous protein dimerizes efficiently. In this paper, construction of a recombinant plasmid which allows detection of the activity of the $\lambda$ chimeric repressor formed by the $\mathbf{N}$-terminal part of $\mathrm{cl}$ fused with a heterologous protein is reported. This construct is interesting due to its potential to be integrated in any target gene of the bacterial host, thus permitting this hybrid assay to be performed, not only in Escherichia coli strains, but in every bacterial genus where the reporter gene can be expressed. In addition, because of its modular construction, this plasmid can be easily modified to be exploitable in many experimental situations, such as in the detection of promoter region activity.
\end{abstract}

Keywords: dimerization, two-hybrid assay, $\lambda$ phage

\section{INTRODUCTION}

Many manifestations of living organisms are the result of protein activities which need the formation of either the protein multimers themselves or macromolecular complexes with other proteins. Various assays (called two-hybrid systems) have been developed both in prokaryotes and in eukaryotes to demonstrate in vivo these protein-protein interactions. One of these systems exploits the structure and properties of the repressor encoded by the $c I$ gene of bacteriophage $\lambda$ (Hu et al., 1990; Longo et al., 1995).

The active $\lambda$ repressor is a homodimer formed by two cI molecules whose $\mathrm{N}$-terminal portion is involved in DNA recognition and binding whereas the $\mathrm{C}$-terminal portion mediates the two subunit dimerizations. Therefore, the $\mathrm{N}$-terminal DNA-binding domain of the $\lambda \mathrm{cI}$ repressor dimerizes inefficiently unless a separate C-terminal dimerization domain is present. Thus, fusion of the cI $\mathrm{N}$-terminal domain with a heterologous protein will result in a functional $\lambda$ repressor, able to strongly bind to its operator and therefore conferring immunity to $\lambda$ infection only when the heterologous protein is able to dimerize efficiently, i.e. only those proteins that mediate efficient dimerization of the chimera in vivo permit survival of the host cell upon infection with $\lambda$ phage (Fig. 1)

Besides the sensitivity to $\lambda$ infection, several systems are available to study the functionality of these chimeric $\lambda$ repressors exploiting a reporter gene under the control of the $\lambda P_{\mathrm{R}}$ or $P_{\mathrm{L}}$ promoter carried by plasmids or by the $\lambda$ prophage itself, integrated in its natural site in the bacterial genome. Although very useful, these systems have strict limitations: in the former case, the plasmid copy number is not easily controlled, and in the latter, they are exploitable only in Escherichia coli K-12 strains permissive to $\lambda$ lysogenization. In addition, the $\lambda \mathrm{cI}$ hybrid assay in its entirety is limited to $E$. coli. It would be interesting to find a strategy which could permit the extension of this kind of investigation to other bacterial genera.

We report the construction of a recombinant plasmid which overcomes these limitations, i.e. the presence of a single copy and potential use in every bacterial genus in which the reporter gene can be expressed. In addition, thanks to its modular structure, this construct exhibits a versatility that makes it exploitable in many experimental situations, such as in the detection of promoter region activity. 


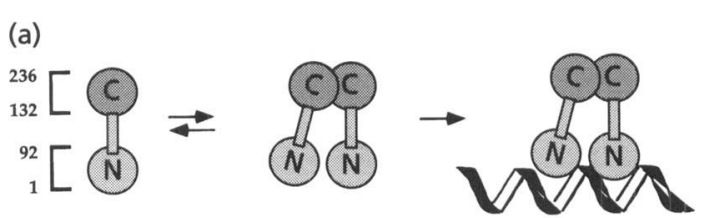

(b)
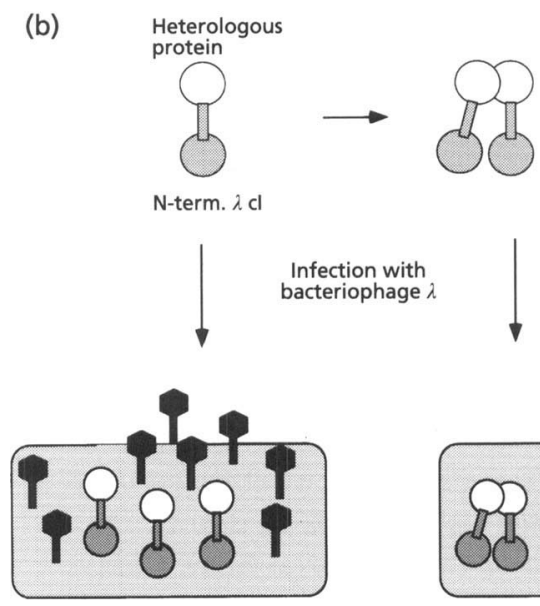

Not immune

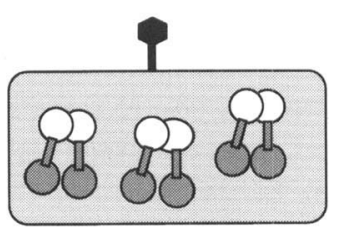

Immune

Fig. 1. $\lambda$ hybrid assay. (a) Mode of $\lambda$ repressor action (re-drawn from Ptashne, 1986). Numbers represent amino acid residues. (b) Scheme of the $\lambda$ hybrid assay. The left-hand side shows heterologous protein constituting the chimeric $\lambda$ repressor which is not able to dimerize: the bacterial cells are sensitive to $\lambda$ infection. On the right-hand side heterologous protein dimerizes and cells are immune.

\section{METHODS}

Bacterial strains, phages and plasmids. Bacterial strains (all $E$. coli $\mathrm{K}-12$ derivatives), phages and plasmids used in this work are listed in Table 1.

Media and chemicals. LB or NB broth, for bacterial cultures and plating, and SM, for bacteria and phage dilutions, were as described by Miller (1972). Ampicillin, chloramphenicol, kanamycin and phosphonomycin (Sigma) were used at 50, 34, 30 and $30 \mu \mathrm{g} \mathrm{ml}^{-1}$, respectively. Synthetic oligonucleotides used in this work are listed in Table 2.

Dimerization assay. Two methods were employed to test protein dimerization: (1) immunity to $\lambda$ infection and (2) measurement of $\beta$-galactosidase activity. Bacterial strains were grown in LB to about $1 \times 10^{8}$ cells $\mathrm{ml}^{-1}$, centrifuged and resuspended in $\mathrm{SM}$ supplemented with $1 \times 10^{-2} \mathrm{M} \mathrm{MgSO}_{4}$ and $5 \times 10^{-3} \mathrm{M} \mathrm{CaCl}_{2}$ and poured with soft agar on $\mathrm{LB}$ plates. Spots of various dilutions of $\lambda$ stock phage were then added and the plates were incubated for $18 \mathrm{~h}$ at $37^{\circ} \mathrm{C}$. The efficiency of $\lambda$ plating was determined as the ratio between the titre of the phage stock on the strain of interest and that on strain $71 / 18$, used as a control. $\beta$-Galactosidase activity assays were performed on bacterial cultures grown in $\mathrm{LB}$ to $\mathrm{OD}_{600} 0.5$, as described by Miller (1972).

General microbiological and DNA recombinant techniques. Standard microbiological and DNA recombinant techniques were as described by Miller (1972) and Sambrook et al. (1989), respectively.

\section{RESULTS}

In order to quantify the dimerization efficiency of a protein, we developed a genetic system based on the repression exerted by the chimeric repressor with the $\mathrm{N}$ terminal part of $\lambda$ cI fused with the heterologous protein to be tested, on the $\beta$-galactosidase synthesis directed by the $\lambda$ operator-promoter $O_{\mathrm{R}} P_{\mathrm{R}}$ region ( $\mathrm{p} \lambda$-lacZ) carried by a plasmid which can easily integrate in a target gene of the bacterial genome.

A $\Delta$ lac bacterial strain was constructed in which a DNA fragment containing the $\lambda$ promoter upstream from the lac $Z$ gene was integrated in the $g l p T$ gene. In this strain, the $\lambda$ promoter governs $\beta$-galactosidase synthesis and the dimerization efficiency can be measured as the ability of the fusion protein to inhibit $\beta$-galactosidase synthesis.

\section{Construction of the PAPA plasmid, carrying p $\lambda$-lacZ}

Plasmid pAPA is a Cam ${ }^{\mathrm{R}}$ derivative of $\mathrm{pBR} 322$ (Bolivar et al., 1977) in which the $\lambda$-operator-promoter $O_{\mathrm{R}} P_{\mathrm{R}}$ region governing $\beta$-galactosidase synthesis was inserted. In addition, a fragment of the E. coli glpT gene was inserted downstream of $l a c Z$. The construction of the plasmid is reported in Fig. 2. Bacterial $\Delta l a c$ strains containing $\mathrm{pAPA}$ constitutively synthesize $\beta$-galactosidase (Table 3).

Digestion of this plasmid with the restriction endonuclease Pst I followed by ligase treatment yields the construct $(5153 \mathrm{bp}$ ) in a circular form which is devoid of its replication origin. This circular DNA was transformed into the 71/18 $\Delta$ lac strain, and about 20-50 chloramphenicol-resistant clones were selected. Since the circular DNA cannot replicate, the $\mathrm{Cam}^{\mathrm{R}}$ clones were derived from a recombination by a simple crossing over between the $g l p T$ fragment of the construct and the $g l p T$ gene of the host chromosome. The integration of the construct confers to the host resistance to chloramphenicol (carried by the construct itself) and to phosphonomycin due to the inactivation of the bacterial glpT gene (Miller, 1972). The actual integration of the construct into the $g l p T$ gene was tested by the absence of plasmid DNA, phosphonomycin resistance and amplification by PCR of a DNA fragment containing both bacterial and plasmid sequences (data not shown).

One important characteristic of pAPA is that the various markers were inserted in pBR322 as modules so that each of them can be substituted, depending on the different needs, without modifying the potentials of the construct itself. For example, the lac $Z$ gene can be easily substituted with another quantifiable expression marker, such as a green fluorescent protein gene or lux, and the target gene can be chosen according to the bacterial strain (or genus) in which the plasmid has to be integrated; various promoters can also be used instead of the $\lambda$ promoter to direct $\beta$-galactosidase synthesis. In the latter case, the pAPA plasmid can also be useful to measure promoter strength or to identify a promoter region, since DNA fragments deriving from a library can also be cloned upstream from lacZ in pAPA. 
Table 1. Bacterial strains, plasmids and phages

\begin{tabular}{|c|c|c|}
\hline Strain/plasmid/phage & Relevant genotype & Source or reference \\
\hline \multicolumn{3}{|l|}{ Strains } \\
\hline $71 / 18$ & $\begin{array}{l}\text { supE thy } \Delta\left(\text { lac-proAB) } \mathrm{F}^{\prime}\left(\text { proAB } B^{+} \text {lacl }\right.\right. \\
\text { lacZ } \mathrm{M} 15)\end{array}$ & Dente et al. (1983) \\
\hline R719 & $71 / 18 \operatorname{glp} T:: \lambda \mathrm{O}_{\mathrm{R}} P_{\mathrm{R}} \operatorname{lac} Z$ & This work \\
\hline RS54 & $s u^{0}$ arad & L. Paolozzi collection \\
\hline \multicolumn{3}{|l|}{ Plasmids } \\
\hline pAPA & pBR322 derivative containing $\lambda O_{\mathrm{R}} P_{\mathrm{R}}$ lac $Z$ & This work \\
\hline pAPAgem & pBR322 derivative containing $\mathrm{p}_{g e m}$ lac $Z$ & This work \\
\hline pAPAgem2 & pBR322 derivative containing pgem 2 ts $l a c Z$ & This work \\
\hline $\mathrm{pMG} 29$ & $\begin{array}{l}\text { pC132 derivative carrying the } \mathrm{N} \text {-terminal } \\
\text { end of the } \lambda \text { repressor }\end{array}$ & This work \\
\hline pC132 & $\begin{array}{l}\text { pBR322 derivative carrying the } 5^{\prime} \text { end of } \lambda c l \\
\text { fused in-frame with the rop gene and } \\
\text { under the control of the lac promoter }\end{array}$ & Longo et al. (1995) \\
\hline pcI-cat & $\begin{array}{l}\text { pC132 derivative harbouring the } c a t \text { gene of } \\
\text { Tn906 in-frame with the } 5^{\prime} \text { portion of } \lambda c I\end{array}$ & This work \\
\hline pcI-gyrB & $\begin{array}{l}\mathrm{pC} 132 \text { derivative harbouring the } \mathrm{gyr} B \text { gene } \\
\text { in-frame with the } 5^{\prime} \text { portion of } \lambda \mathrm{cl}\end{array}$ & This work \\
\hline pcI-gyrB $\Delta$ & $\begin{array}{l}\text { pC132 derivative harbouring the first } 43 \text { aa } \\
\text { of GyrB in-frame with the } N \text {-terminal } \\
\text { portion of } \lambda \mathrm{cI}\end{array}$ & This work \\
\hline pcI-ftsA & $\begin{array}{l}\text { pC132 derivative harbouring the } f t s A \text { gene } \\
\text { in-frame with the } 5^{\prime} \text { end of } \lambda \mathrm{cl}\end{array}$ & This work \\
\hline pcI-zipA & $\begin{array}{l}\text { pC132 derivative harbouring the } z i p A \text { gene } \\
\text { in-frame with the } 5^{\prime} \text { end of } \lambda \mathrm{cl}\end{array}$ & This work \\
\hline $\mathrm{pcI}_{857}$ & $\begin{array}{l}\text { p15A Kan }{ }^{\mathrm{r}} \text { derivative harbouring the } \lambda c I_{857} \\
\text { gene }\end{array}$ & $\begin{array}{l}\text { Provided by G. Cesareni, } \\
\text { Dipartimento di Biologia, } \\
\text { Università "Tor Vergata", } \\
\text { Roma, Italy }\end{array}$ \\
\hline \multicolumn{3}{|r|}{ (N) } \\
\hline$\lambda$ ref & Wild-type for immunity region & L. Paolozzi collection \\
\hline$\lambda$ vir & $\begin{array}{l}\text { v1 v2 v3; virulent phage insensitive to } \lambda \\
\text { repressor }\end{array}$ & L. Paolozzi collection \\
\hline$\lambda i_{434}$ & $\lambda$ heteroimmune; insensitive to $\lambda$ repressor & L. Paolozzi collection \\
\hline
\end{tabular}

Table 2. Synthetic oligonucleotides used for pAPA construction

\begin{tabular}{|lllrl|}
\hline Primer no. & \multicolumn{1}{c}{ Sequence } & Gene & Position (nt) & \multicolumn{1}{c|}{ Site } \\
\hline 1 & CGGGATCCATGATTACGGATTCACTGG & lacZ & 1288 & BamHI \\
2 & GCGTCGACGCGAAATACGGGCAGAC & $l a c Z$ & 4396 & Sall \\
3 & CCCAAGCTTTAAGGCGACGTGCGTCC & $\lambda \mathrm{O}_{\mathrm{R}} P_{\mathrm{R}}$ & 37880 & HindIII \\
4 & CGGGATCCCATACAACCTCCTTAGTAC & $\lambda \mathrm{O}_{\mathrm{R}} P_{\mathrm{R}}$ & 38044 & BamHI \\
5 & CCCAAGCTTTTGGCGAAAATGAGACG & cam & -124 & HindIII \\
6 & AACTGCAGCACCAGGCGTTTAAGGGC & $c a m$ & 702 & $P$ st \\
7 & GCGTCGACTTATCGTCGATTGCGC & $g l p T$ & 231 & Sall \\
8 & GCGTCGACTGCAGACCGATCAGCATC & $g l p T$ & 1281 & PstISalI \\
\hline
\end{tabular}

\section{Dimerization assay}

In order to test the efficiency of our construct in detecting dimerization with the $\lambda$ hybrid repressor system, we have assayed various proteins. Some of these were already known to be able to dimerize, such as GyrB
(Champoux, 1978), Rop (Castagnoli et al., 1989) and Cat (Leslie, 1990); the behaviour of FtsA (Wang et al., 1997) and ZipA (Hale \& de Boer, 1997) was unknown in terms of their ability to self-interact. The respective genes were amplified by PCR from the RS54 bacterial strain and cloned in-frame with the $5^{\prime}$ end of the $\lambda c I$ 

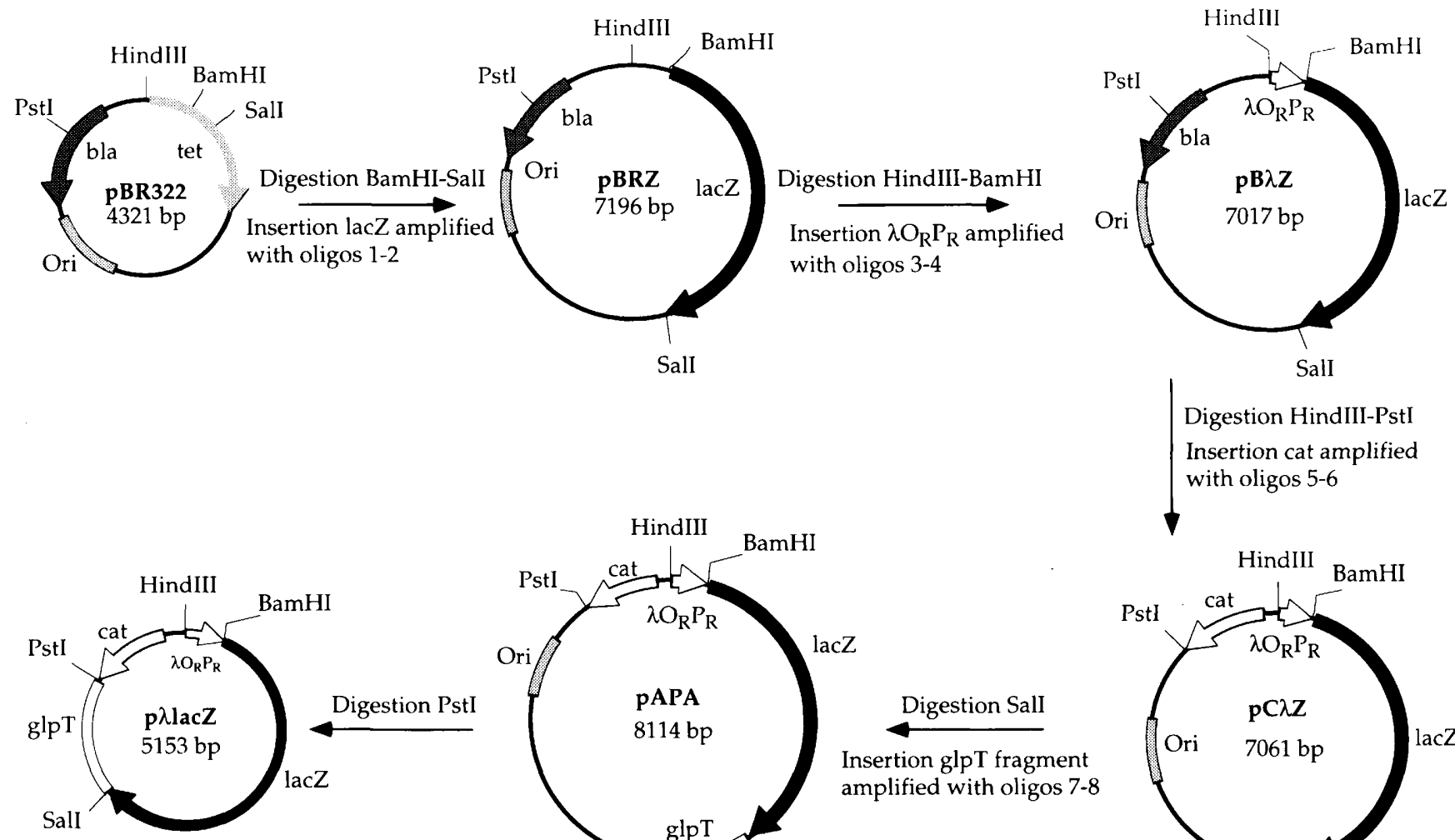

Integrative construct
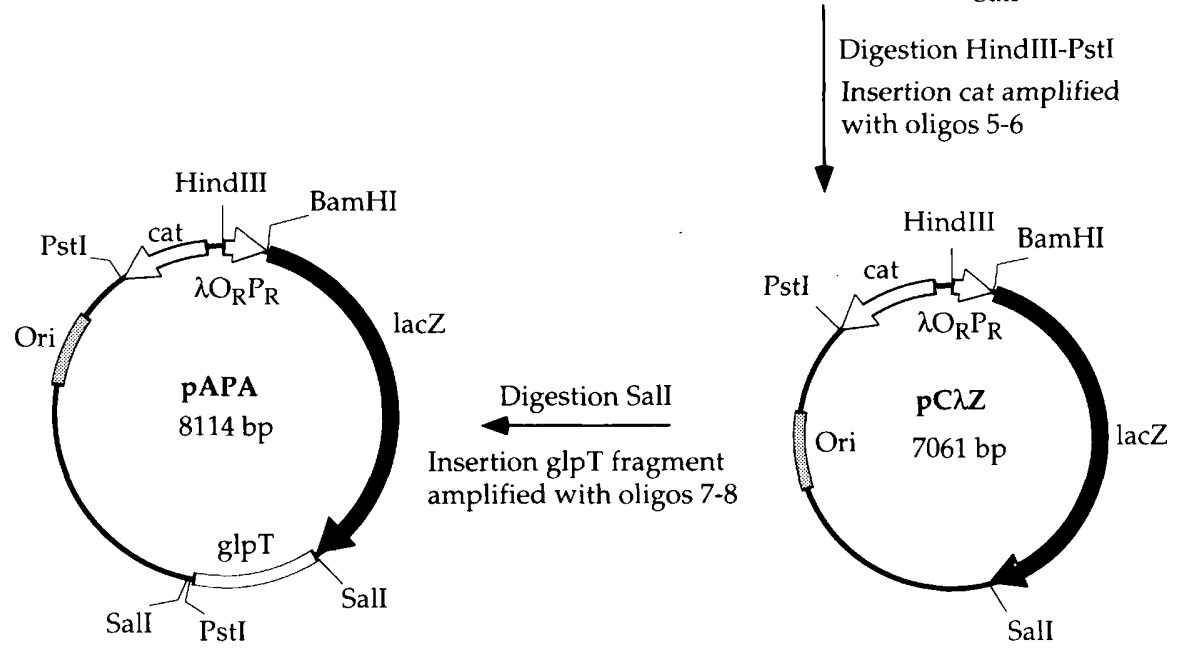

Fig. 2. Construction of the PAPA plasmid and its integrative derivative. The synthetic oligonucleotides indicated in the figure are reported in Table 2.

\section{Table 3. Two-hybrid assay}

The Miller units of $\beta$-galactosidase reported are the mean of five independent determinations. The efficiency of $\lambda$ plating was determined as described in Methods.

\begin{tabular}{|c|c|c|}
\hline Bacterial strain & $\begin{array}{c}\text { Efficiency of } \\
\lambda \text { plating }\end{array}$ & $\begin{array}{c}\beta \text {-Galactosidase } \\
\text { (Miller units) }\end{array}$ \\
\hline $71 / 18$ & 1 & - \\
\hline $71 / 18(\mathrm{pAPA})$ & 1 & 7114 \\
\hline R719 & 1 & 5329 \\
\hline R719(pMG29) & 1 & 4308 \\
\hline $\mathrm{R} 719\left(\mathrm{pcI}_{857}\right)$ & $<1 \times 10^{-9}$ & 82 \\
\hline R719(pC132-rop) & $<1 \times 10^{-9}$ & 186 \\
\hline R719(pcI-cat) & $<1 \times 10^{-9}$ & 117 \\
\hline R719(pcl-gyrB) & $<1 \times 10^{-9}$ & 382 \\
\hline R719(pcI-gyrB $\Delta)$ & $0 \cdot 8$ & 1882 \\
\hline R719(pcI-ftsA) & 0.5 & 602 \\
\hline R719(pcl-zipA) & 1 & 1294 \\
\hline
\end{tabular}

gene in plasmid pC132. Plasmid $\mathrm{pcI}_{857}$, harbouring the $\lambda$ repressor carrying the 857 thermosensitive mutation, was used as a control.

Table 3 reports the $\beta$-galactosidase activities measured in strain R719 and in its derivatives containing either

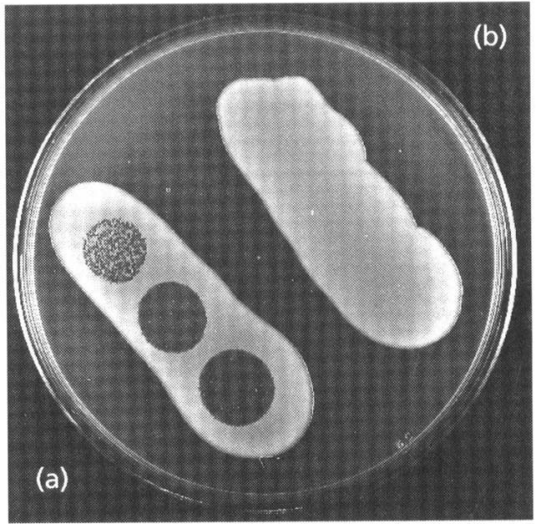

Fig. 3. Dimerization assay. Sensitivity to $\lambda$ infection of the bacterial strain carrying the plasmid encoding the chimeric $\lambda$ repressor. Phage spots contain $10 \mu \mathrm{l}$ of successive dilutions of a $\lambda$ phage stock from $1 \times 10^{9}$ to $1 \times 10^{5}$ phage $\mathrm{ml}^{-1}$. (a) Control: $71 / 18$ bacterial strain without plasmid; (b) $71 / 18$ (pcl-cat). The figure is representative of the other $\mathrm{pcl}$ derivatives tested in this work.

pcI $_{857}$ or plasmids carrying the N-terminal part of $\mathrm{cl}$ fused with the various proteins. As shown in the table, the results obtained by testing the immunity to $\lambda$ infection (Fig. 3) agree with those obtained by measuring 
the $\beta$-galactosidase activity, i.e. the plasmid carrying chimeric repressors able to confer immunity to $\lambda$ also inhibits $\beta$-galactosidase synthesis. As expected, all the proteins known to dimerize form a functional $\lambda$ repressor and inhibit $\beta$-galactosidase synthesis, whereas $\mathrm{Gyr} B \Delta$, which is unable to dimerize, does not substantially affect the enzyme synthesis. From these results we can conclude that the division protein $\mathrm{ZipA}$ does not dimerize, while the behaviour of FtsA may suggest a weak interaction among protein monomers. Strain R719 has already been used to test the dimerization ability of FtsZ, fused with the N-terminal part of $\lambda \mathrm{cI}$, and to characterize $f t s Z$ mutants unable to dimerize (Di Lallo et al., 1999).

The same results were obtained when the plasmid was inserted in another $E$. coli locus, the gal gene. Integration in gal was performed by replacing the plasmid module containing the $g l p T$ gene fragment with gal and selecting the $\mathrm{Cam}^{\mathrm{R}} \mathrm{Gal}^{-}$clones after transformation with the integrative construct (data not shown).

\section{Use of a PAPA plasmid derivative to evaluate promoter strength}

The pAPA plasmid was used to compare the strength of the wild-type gem promoter of bacteriophage Mu with that of the mutated gem 2 ts, which carries an A to $G$ transition in position -44 of the promoter region ( $\mathrm{La}$ Valle et al., 1996).

The module of pAPA containing the $\lambda$-operatorpromoter $O_{\mathrm{R}} P_{\mathrm{R}}$ region was substituted with the Mu gem promoter by digesting the plasmid with HindIII and $B a m \mathrm{HI}$ restriction endonucleases and religating the $6840 \mathrm{~kb}$ fragment obtained with the $234 \mathrm{bp}$ DNA fragment containing the gem promoter obtained by PCR amplification from either $\mathrm{Mu}$ wild-type or the $\mathrm{Mu}$ gem2ts mutant.

Results show that in the bacterial strain containing pAPAgem, only about 30 Miller units of $\beta$-galactosidase are produced, as expected from the sequence analysis of this promoter region, which suggested that $\mathrm{p}_{\text {gem }}$ is a weak promoter. $\beta$-Galactosidase synthesis was further reduced to about 15 Miller units with pAPAgem2, which carries the mutated gem promoter.

\section{DISCUSSION}

The pAPA plasmid, described in this paper, allows the study of various aspects of gene expression and proteinprotein interactions, so as to define the strength of the interaction itself in the two-hybrid assay. In fact, in this paper, we constructed various proteins fused with the N-terminal part of the $\lambda$ cI repressor. Protein dimerization and the strength of their interactions are deduced by the ability of the chimeric repressor to shut off the lac $Z$ expression driven by the $\lambda$ promoter, i.e. by its ability to bind the $\lambda$ operator site. It is important to note that this approach is sensitive to both the copy number of the chimeric protein produced and the relative folding ability of the fusion protein created also regarding the multimeric nature of the dimerizing proteins. As far as the copy number of the chimeric repressor is concerned, we have recently shown by Western blotting that the amount of the fusion protein cI-FtsZ present in the cell is similar to that of FtsZ ( $\mathrm{Di}$ Lallo et al., 1999), and since in every case the fusion proteins are cloned in the same vector and in the same host strain, this value can be roughly extended to all the other fusion proteins. Moreover, since Rop protein is a dimer, Cat a trimeric protein and FtsZ a polymer, this $\lambda$ hybrid assay seems to be able to reveal any proteinprotein interaction.

The pAPA plasmid is also suitable for studying promoter strength in vivo, as shown for both strong and weak promoters. In fact, when the $\lambda P_{\mathrm{R}}$ promoter drives the $\beta$ galactosidase synthesis, more than 5000 Miller units are produced, whereas the weak $\mathrm{p}_{\text {gem }}$ promoter is responsible for the production of 30 Miller units $\beta$ galactosidase.

In addition, the modular construction gives to pAPA (i) the plasticity for many experimental requirements (as free plasmid or integrated in the host genome), (ii) the use of various reporter genes and (iii) easy substitution of the replication origin. For all of these reasons, the pAPA plasmid can be very useful, and it is also potentially applicable to bacterial strains of biotechnological interest.

\section{ACKNOWLEDGEMENTS}

We are most grateful to D. Anderluzzi for her helpful discussions and to $M$. Lo Ponte for careful revision of the manuscript. This work was partially supported by funds from Glaxo-Wellcome.

\section{REFERENCES}

Bolivar, F., Rodriguez, R. L., Greene, P. J., Betlach, M. C., Heyneker, H. L. \& Boyer, H. W. (1977). Construction and characterization of new cloning vehicles. II. A multipurpose cloning system. Gene 2, 95-113.

Castagnoli, L., Scarpa, M., Kokkidanis, M., Banner, D. W., Tsernoglou, D. \& Cesareni, G. (1989). Genetic and structural analysis of the ColE1 Rop (Rom) protein. EMBO J 8, 621-629.

Champoux, J. J. (1978). Proteins that affect DNA conformation. Annu Rev Biochem 47, 449-479.

Dente, L., Cesareni, G. \& Cortese, R. (1983). pEMBL: a new family of single stranded plasmids. Nucleic Acids Res 11, 1645-1655.

Di Lallo, G., Anderluzzi, D., Ghelardini, P. \& Paolozzi, L. (1999). FtsZ dimerization in vivo. Mol Microbiol 32, 265-274.

Hale, C. A. \& de Boer, P. A. (1997). Direct binding of FtsZ to ZipA, an essential component of the septal ring structure that mediates cell division in E. coli. Cell 88, 175-185.

Hu, J. C., O'Shea, E. K., Kim, P. S. \& Sauer, R. T. (1990). Sequence requirements for coiled-coils: analysis with $\lambda$ repressor-GCN4 leucine zipper fusions. Science 250, 1400-1403.

La Valle, R., Fabozzi, G., Ghelardini, P. \& Paolozzi, L. (1996). Bacteriophage $\mathrm{Mu}$ gem $2 \mathrm{ts}$, which induces synchronous cell 
division in the infected host, is mutated in the gem operon promoter. Res Microbiol 147, 615-618.

Leslie, A. G.W. (1990). Refined crystal structure of type III chloramphenicol acetyltransferase. J Mol Biol 213, 167-186.

Longo, F., Marchetti, M. A., Castagnoli, L., Battaglia, P. A. \& Gigliani, F. (1995). A novel approach to protein-protein interaction: complex formation between the $\mathrm{p} 53$ tumour suppressor and the HIV Tat proteins. Biochem Biophys Res Commun 206, 326-334.

Miller, J. H. (1972). Experiments in Molecular Genetics. Cold Spring Harbor, NY: Cold Spring Harbor Laboratory.
Ptashne, M. (1986). A Genetic Switch: Gene Control and Phage $\lambda$, vol. 2, p. 263. New York: Cell Press.

Sambrook, J., Fritsch, E. F. \& Maniatis, T. (1989). Molecular Cloning: a Laboratory Manual, 2nd edn. Cold Spring Harbor, NY: Cold Spring Harbor Laboratory.

Wang, X., Huang, J., Mukherjee, A., Cao, C. \& Lutkenhaus, J. (1997). Analysis of the interaction of FtsZ with itself, GTP, and FtsA. J Bacteriol 179, 5551-5559.

Received 26 November 1998; revised 9 February 1999; accepted 16 February 1999. 